\title{
Testimonio literario latinoamericano: prefiguraciones históricas del género en el discurso revolucionario de los años sesenta
}

\author{
Victoria García
}

La fundación del testimonio en el campo literario latinoamericano, cuyos primeros indicios datan de fines de los sesenta, la institucionalización de la revolución cubana, en que su proyección hacia el conjunto de Latinoamérica constituyó un problema central. Este artículo estudia las precondiciones políticas del testimonio literario. En particular, analiza aspectos del discurso revolucionario cubano que anticipan operaciones características del género, en los modos como representan la relación entre literatura y política, y en las figuras de sujetos de discurso que proponen como encarnaciones de tal vínculo. El trabajo introduce, primero, la cuestión de la revolución cubana, en cuanto al estatuto modélico que adquirió en Latinoamérica en los sesenta. Segundo, examina el posicionamiento literario representado por el testimonio, como corolario de una reconsideración reflexiva de ciertos escritores y críticos latinoamericanos sobre su papel histórico. Tercero, considera tres documentos representativos del proceso y su proyección continental: La historia me absolverá, de Fidel Castro, y Pasajes de la guerra revolucionaria y el Diario de Bolivia, de Ernesto Guevara. El análisis muestra la configuración de un sujeto revolucionario cuya legitimidad surge no sólo de una experiencia política enunciada en la forma del testimonio, sino de particulares modos de vivir y representar la literatura en el contexto de la práctica revolucionaria. Hacia el final de esa década, son esos criterios de legitimación del discurso los que reafirman el campo literario continental, en la institucionalización del testimonio como su género privilegiado.

PALABRAS CLAVE: testimonio, revolución cubana, discurso revolucionario, literatura, género. 
The foundation of testimonio in Latin American literary field, initiated at the end of the " 60 , makes part of the institutionalization of the Cuban revolution, process where its projection to the rest of Latin America constitued a central problem. This paper studies political preconditions of testimonio. In particular, it analizes certain aspects of Cuban revolutionary discourse that anticipate features eventually developed by the literary genre, in the ways the relation between literature and politics is represented, and in the subjects of discourse that are proposed as embodiments of such relation. The paper introduces the question of Cuban revolution, as regards the exemplary status it acquired in Latin America during the sixties. Then, it examines the literary positioning represented by testimonio, as the corollary of a reflexive reconsideration operated by some Latin American writers and critics, concerning their historical role. Finally, it considers three representative documents of Cuban revolution and its continental projection: History will absolve me, by Fidel Castro, and Reminiscences of the Cuban revolutionary war and Bolivian diary, by Ernesto Guevara. We show the textual configuration of a revolutionary subject whose legitimity emerges not only from a political experience which testimony enunciates, but also from particular ways of living and representing literature in the context of a revolutionary practice. In the end of the sixties, the continental literary field would reaffirm such features as its discourse legitimating criteria, during the institutionalization of testimonio as its privileged genre.

KEYWORDS: testimonio, Cuban revolution, revolutionary discourse, literature, genre.

Fecha de recepción: 16 de julio de 2013

Fecha de aceptación: 27 de septiembre de 2013 
Victoria García

Universidad de Buenos Aires

Facultad de Filosofia y Letras

\section{Testimonio literario latinoamericano: prefiguraciones históricas del género en el discurso revolucionario de los años sesenta}

Introducción: la ley de la Revolución latinoamericana, o Cuba da testimonio

En su producción de un sentido distinto para el orden histórico en que se inscribe, y como efecto de sus prácticas y discursos, la Revolución renueva los modelos instalados de verdad y justicia sociales. Así, su denuncia de una injusticia que remite al pasado, como resultante del accionar político enemigo - ahora: contrarrevolucionario- propone, en cambio, lo "justo" y "verdadero" del presente histórico que el mismo discurso revolucionario configura. Se trata, entonces, de desordenarlo todo, pero afianzando en la temporalidad prolongada de un proceso el momento epifánico del triunfo, o la ruptura que la Revolución opera entre lo que define como su "antes y después" históricos.

$\mathrm{Si}$, de ese modo, un proceso revolucionario ha de consolidarse como duradero, uno de sus requisitos básicos es la construcción de un relativo consenso sobre la legitimidad de la acción en marcha; más aún, sobre su estatuto de ley histórica. De allí la "irresistibilidad" que, según señala Hannah Arendt, ha recubierto la noción moderna de la revolución. En efecto, los procesos revolucionarios han aparecido frecuentemente como irreductibles a la capacidad de los sujetos de torcer el rumbo de la 
historia: leyes preestablecidas de un destino que convoca a los hombres a ser cumplido, y que ellos actualizan al recorrer, infalibles, la dirección revolucionaria predefinida para el trayecto histórico (Sobre la revolución, 62).

La manera peculiar de representación de la historia moderna que describe la revolución, halla en Cuba, para el ámbito latinoamericano, una ejemplificación cabal. Triunfal en 1959, la revolución cubana procuró en lo sucesivo instituirse como ley de una experiencia política que el conjunto de la región habría de atravesar, más tarde o más temprano, bajo el paradigma de la isla. No obstante, frente al proceso revolucionario inaugurado por Cuba como destino insoslayable de los países latinoamericanos, era notorio para sus actores políticos que la realización de ese fin, más que asegurada por la fuerza ineluctable de una ley, definía un decurso posible, supeditado a su propia agencia, y a la imprevisibilidad compleja de la condición histórica. ${ }^{1}$

Coexistían, entonces, la atención al riesgo presente de la derrota y la confianza en la posibilidad de un triunfo revolucionario que, atestiguada por el caso cubano, reivindicaba su justicia histórica para todo el conjunto del continente. La realización de un objetivo político tal requería un dispositivo discursivo eficaz que, durante los años sesenta latinoamericanos, buscó expandir la Revolución desde su Cuba de origen hacia la extensión de la región, y Latinoamérica devino, así, destinataria de una discursividad revolucionaria cubana de cuya reproducción participaron, además, amplios sectores políticos y culturales ligados a los movimientos de izquierda del continente. En efecto, es conocido el papel relevante que el campo intelectual cumplió en la difusión regional del imaginario revolucionario vinculado al ejemplo de Cuba, junto al tono político que dominó progresivamente en la creación artística

${ }^{1}$ La cuestión de la Revolución Cubana como caso extraordinario o eslabón de un proceso más amplio, que concerniría a toda Latinoamérica, se resume en "Cuba, ¿excepción histórica o vanguardia en la lucha contra el colonialismo?”, artículo que Ernesto Guevara publicó en 1961, refutando la tesis de la excepcionalidad cubana (Cfr. $\mathrm{La}$ revolución cubana, 18). Sobre la relación entre historia y sujeto como condiciones de la revolución en su acepción guevarista, Lowy ha señalado su carácter dialéctico: la praxis revolucionaria es producto de condiciones dadas y creadora de nuevas condiciones ( $E l$ pensamiento del Che, 107). 
del período. ${ }^{2}$ Asimismo, y en lo que específicamente nos ocupa, se ha señalado en el surgimiento de la literatura testimonial, instituida como género en Cuba hacia el final de la década de 1960, una manifestación cabal de dicho proceso (Aymerich, La memoria en el espejo..., 27).

Sin duda, la institucionalización del testimonio constituyó, al finalizar los sesenta, el corolario de una revisión que, durante la etapa, un importante conjunto de escritores y críticos operó sobre el significado de su propia tarea, y que tendía a cuestionar la escisión de la literatura respecto de otros espacios de la práctica social. Así, especialmente la política, y las modalidades discursivas involucradas en la consecución de la tarea prorrevolucionaria, cobraron en los años sesenta latinoamericanos un rol modélico para la producción literaria del período. El surgimiento del testimonio da cuenta de ello, con las implicaciones que describimos en el apartado que sigue.

\section{Por una nueva legitimidad literaria: testimonio y política revolucionaria en la década de 1960}

La institucionalización del testimonio como género literario latinoamericano constituyó una instancia político-cultural de la consolidación del proceso revolucionario cubano, en que su proyección hacia el conjunto de la región representó un problema central. En ese sentido, se ha observado el papel crucial que Casa de las Américas desempeñó en la creación del género, con la introducción de una categoría específica "Testimonio" en la edición de 1970 de su certamen literario. ${ }^{3}$ Asimismo, fue decisivo el ensayo "La novela testimonio: socio-literatura", que Miguel Barnet publicó en 1969, como colaborador de la revista de la Unión de Artistas y Escritores de Cuba. Allí, el autor proveía una justificación teórica de ciertos procedimientos de escritura practicados por él mismo

${ }^{2}$ Claudia Gilman provee una caracterización de los años sesenta y setenta como una época singular de la intelectualidad y la literatura latinoamericanas, en que los desplazamientos en la función social de dichos campos se ligaron decisivamente a la incidencia de la Revolución Cubana (Entre la pluma y el fusil..., 28).

${ }^{3}$ Para una historización sucinta del género testimonial, Cfr. Aymerich (La memoria en el espejo, 31 y ss.). 
en Biografía de un cimarrón (1966) y Canción de Rachel (1969), pero, además, legitimaba todo un posicionamiento literario, cuya realización resumía, en sus palabras: "un desentrañamiento de la realidad, tomando los hechos principales, los que más han afectado la sensibilidad de un pueblo y describiéndolos por boca de uno de sus protagonistas más idóneos" (Barnet, "La novela testimonio...", 108).

Hay que resaltar la singularidad histórica de esta inicial institucionalización del testimonio, frente al impulso crítico que el género recibió casi tres décadas más tarde, y adjudicó a Me llamo Rigoberta Menchú su ejemplaridad privilegiada. ${ }^{4}$ Así, en el campo cubano del final de los años sesenta, y para cierto conjunto afín de escritores y críticos de otros países latinoamericanos, la instalación del testimonio integraba una reflexión vasta del sector letrado sobre su rol histórico, que subrayaba la caducidad de las formas tradicionales de la comunicación literaria - sobre todo, de la narrativa de ficción - para dar cuenta de la especificidad cultural y política de la región. La renovación política, que se percibía como marca continental propia, parecía requerir su correlato en las características de la producción literaria, ya que, de otro modo, ésta corría el riesgo de volverse anacrónica. "Los géneros que tenemos aquí no corresponden más al estado actual de la literatura, como existe" (Rama, “Conversación...”, 123), observaba, en esa dirección, el crítico Hans Magnus Enzensberger, en los debates que en Casa de las Américas prepararon la inclusión del testimonio en su premio literario.

De cara, pues, a la necesidad percibida de una literatura característicamente latinoamericana, el género en creación proponía, primero, un procedimiento de relectura: era cuestión de rastrear en espacios discursivos tradicionalmente desdeñados por los círculos literarios, los materiales idóneos para la representación del proceso histórico latinoamericano. Se construía de ese modo un corpus genérico retroactivo, conformado por textos que, en su momento inicial de circulación, ha-

${ }^{4}$ La centralidad de Me llamo Rigoberta Menchú es frecuente en la bibliografía sobre testimonio latinoamericano, donde, sin embargo, el alcance otorgado a la denominación genérica resulta inestable. A propósito, Sklodowksa se ha referido a las dificultades críticas para la construcción del corpus testimonial (Testimonio hispanomericano..., 64), problema sobre el cual hemos formulado una fundamentación teórico-analítica ligada al estatuto histórico y metadiscursivo de los géneros (Cfr.. "Testimonio literario...", 2012). 
bían sido "extraliterarios": periodísticos -como Operación masacre, de Rodolfo Walsh (1957) - ligados a las ciencias sociales - Juan Pérez. Jolote, de Ricardo Pozas (1948), y la ya citada Biografía de un cimarrón, de Barnet - o a la militancia política - canónicamente, los Pasajes de la guerra revolucionaria, de Ernesto Guevara (1963). ${ }^{5}$

Al mismo tiempo, la relectura literaria de esta serie "extraliteraria" de materiales, y el corpus que de tal operación resultaba, proveía una serie de modelos para la ulterior producción bajo la nueva categoría genérica. En este sentido, el certamen de Casa de las Américas jugó un importante rol, pues promovió la escritura testimonial, fijando pautas para el género que se instituía, y además intervino, con la colección "Premio" de su fondo editorial, en la publicación de los textos, y su puesta en circulación regional.

Subrayemos, pues, que una de las condiciones básicas de la institucionalización inicial del testimonio fue el reconocimiento que, hacia el final de la década de 1960, los actores del campo literario operaron sobre las cuestiones políticas de la Latinoamérica del período. Más aún, es posible afirmar que, al menos en parte, el género testimonial se crea como reescritura literaria de la discursividad política revolucionaria que inaugura el proceso cubano, en que las figuras de Ernesto Guevara y Fidel Castro ocuparon un papel preponderante.

En esa orientación, John Beverley (Testimonio..., 32) ha situado en la publicación como libro de la obra escrita de Ernesto Guevara un elemento decisivo para la eventual institucionalización literaria del testimonio. La edición de los textos de Guevara se inició al comenzar la década de 1960 con La guerra de guerrillas y Pasajes de la guerra revolucionaria, y prosiguió luego de su muerte en 1967, con el Diario de Bolivia y varias compilaciones de sus obras completas. ${ }^{6}$ La puesta

${ }^{5}$ La retroacción genérica es, para Schaeffer (¿Qué es un género literario?, 97), el fenómeno por el cual los textos reciben nuevas categorizaciones genéricas a la luz de transformaciones del contexto histórico, transformaciones que incluyen los desplazamientos en el sistema de géneros vigente en el campo literario.

${ }^{6}$ Las compilaciones incluyen: la Obra revolucionaria editada por Fernández Retamar en México (Era, 1967), una Obra completa publicada en Buenos Aires (Del Plata, 1967), los Relatos del Che; obras completas editados en Montevideo (Sandino, 1970) y El libro verde olivo (México, Diógenes, 1970). 
en libro de la obra del Che tendía a recalcar su faceta literaria, de modo tal que la construcción de la figura heroica del guerrillero se ligaba a la canonización de su rol de escritor. Así, en el prólogo a la Obra revolucionaria de Guevara (1967), editada en México, Fernández Retamar, sostenía sobre los Pasajes que "es también el artista quien lo escribe", y colocaba al libro dentro del canon cubano reciente: "Éste es el libro más conmovedor publicado en Cuba en estos años", afirmaba (5). En el mismo sentido pueden entenderse ciertas valoraciones sobre el Che que circularon en las revistas literarias publicadas en homenaje al guerrillero, con motivo de su fallecimiento. ${ }^{7}$

La figura de Fidel Castro recibió un tratamiento análogo por parte de ciertos escritores y críticos del período, que hallaron un valor literario en las alocuciones del líder cubano. En esa línea, puede mencionarse la intervención del boliviano Óscar Collazos en la difundida polémica mantenida con Vargas Llosa y Cortázar, donde el escritor señalaba que los discursos de Castro hacían surgir "una manera de decir, un discurso literario, un ordenamiento y una reiteración verbal, una modelación de la palabra en el plano del discurso político que, a su vez, podría ser la fuente de un tipo de literatura cubana dentro de la revolución" (Literatura en la revolución..., 17). ${ }^{8}$ Otros reconocimientos literarios del discurso del gobernante cubano se exhibieron en procedimientos puestos en práctica en la escritura. Así, Juan Carlos Quintero Herencia (Fulguración...) ha encontrado en las denominadas "Palabras a los intelectuales" una anticipación de la estética testimonial, tal como la inició más tarde Miguel Barnet. En esa célebre alocución, Castro había promovido una escritura a cargo de los sectores marginados por la cultura letrada,

${ }^{7}$ Nos referimos al número 46 de Casa de las Américas, de enero-febrero de 1968, íntegramente dedicado al Che, así como al número 47 de la misma revista, y el número 4 de Unión, de diciembre de 1967, que incorporan varias notas dedicadas a la figura de Guevara. Acerca de la importancia de la figura de Guevara en la historia del testimonio latinoamericano, véase Morejón Arnaiz (“Testimonio...", 101 y ss.).

${ }^{8}$ El valor literario de los discursos de Fidel Castro adquiriría estatuto teórico en la conceptualización de la literatura latinoamericana que Fernández Retamar elaboró desde la primera mitad de la década de 1970, en lo que luego sería Para una teoría de la literatura hispanoamericana. Allí, el crítico incorpora las alocuciones de Fidel entre las manifestaciones "ancilares" o "marginales" de la literatura continental, que definen, según él, su específico carácter (183 y ss.). 
asociada a una figura de esclavo anciano y testigo de la historia, que, efectivamente, protagonizaría luego Biografía de un cimarrón. ${ }^{9}$

De ese modo, la vocación política de un sector del campo literario latinoamericano de los años sesenta, y las redefiniciones del estatuto del escritor que tal vocación conllevaba, favorecieron la construcción de un renombre de escritores para los representantes mayores de la política revolucionaria cubana. Castro y Guevara se situaron, doblemente, como "autores" de la Revolución: responsables éticos y jurídicos de la obra política magnánima que implicaba hacer justicia histórica en Cuba y su continente, pero, además, de la obra literaria que edificaba la utopía de su relato.

Se ha señalado, en efecto, el lugar de coautoría que el poder revolucionario tendió a asumir en la práctica literaria de los años sesenta y setenta latinoamericanos, así como la desvalorización de escritores e intelectuales sobre su propia tarea, desacreditada frente a la autoridad máxima atribuida a la acción política (Gilman, Entre la pluma y el fusil..., 357; Morejón Arnáiz, "Testimonio...", 99). Ahora bien, dejando de lado las cuestiones del reconocimiento literario e intelectual del discurso político contemporáneo, es indudable que dicho reconocimiento, incluso con los desfases que podía efectuar sobre el sentido "original" del discurso de los líderes revolucionarios, no surgía ex nihilo, sino de representaciones del vínculo entre literatura y política que ellos pusieron en circulación en el contexto latinoamericano de los años sesenta. Se trata de un conjunto de operaciones discursivas efectivamente identificables en ciertas zonas del discurso de Fidel Castro y Ernesto Guevara, y que, paulatinamente a través del período, procurarían condiciones políticas propicias para la institucionalización del testimonio hacia el final de la década.

${ }^{9}$ Decía en esa oportunidad Castro: "En días recientes nosotros tuvimos la experiencia de encontrarnos con una anciana de 106 años que había acabado de aprender a leer y a escribir, y nosotros le propusimos que escribiera un libro. Había sido esclava, y nosotros queríamos saber cómo un esclavo vio el mundo cuando era esclavo [...]. Creo que puede escribir una cosa tan interesante que ninguno de nosotros la podemos escribir. Y es posible que en un año se alfabetice y además escriba un libro a los 106 años - ¡esas son las cosas de las revoluciones! - y se vuelva escritora y tengamos que traerla aquí a la próxima reunión" (apud Quintero Herencia, Fulguración...,371). 
A esa cuestión nos dedicamos en los próximos apartados, a partir del análisis de tres documentos representativos del proceso revolucionario cubano y su expansión continental: La historia me absolverá, de Fidel Castro, y Pasajes de la guerra revolucionaria y el Diario del Che en Bolivia, de Ernesto Guevara. Los tres textos circularon como libros, formato que abonaba una posible lectura literaria, no sólo en Cuba sino también en otros países de América Latina, durante la década de 1960. Por otra parte, todos ellos presentan un aspecto testimonial, pues narran hechos del quehacer revolucionario desde la posición legítima del haber estado allí que tanto en su individualidad como en la dupla que conforman, Castro y Guevara encarnan de modo paradigmático.

Invención de un futuro en La historia me absolverá:

Fidel y la causa revolucionaria que comienza

Es sabido que, antes de su triunfo en 1959, el proceso político de la revolución cubana ubica su inicio en julio de 1953, en los sucesos del asalto al cuartel Moncada (Guevara, La revolución cubana, 10). Efectuado por un grupo de rebeldes contra el régimen de Batista que lideraba Fidel Castro, el asalto culminó en un fracaso, debido a la condición militar desventajosa de los sublevados, y a ciertos errores tácticos. Sin embargo, aun con la eventual derrota implicada en el episodio del Moncada, éste representa un momento fundacional de la Revolución, propulsor de ciertas matrices de sentido que, incluyendo el liderazgo de Castro, orientarán la política revolucionaria cubana luego del triunfo alcanzado en $1959 .{ }^{10}$

La historia me absolverá constituye una pieza crucial en ese contexto revolucionario de fundaciones: se trata del alegato final de Fidel Castro, que esgrimió en su propia defensa en la última sesión del juicio a los participantes en el asalto, realizada el 16 de octubre de 1953. Pro-

${ }^{10}$ El Movimiento 26 de Julio que, liderado por Fidel Castro, impulsó el proceso revolucionario, reformuló varios de los postulados políticos que habían orientado el asalto al Moncada (Guevara, La revolución cubana, 89 y ss.), además de tomar su nombre de la fecha de la operación. Sobre el sentido fundador de los hechos del Moncada, en perspectiva discursiva, véase Giraudo (Revolución..., 39). 
ducido inicialmente en forma oral, en el espacio restringido de la sesión del juicio, el texto se editó por primera vez en Cuba en 1954 por indicación de Castro, quien cumplía su sentencia en la Isla de Pinos. A esa publicación inicial siguió, después de 1959, un importante número de ediciones en Cuba y otros países de América Latina,,${ }^{11}$ como parte de la constante reescritura del proceso político cubano en la década de 1960, y de la proyección continental de su causa revolucionaria ejemplar.

De hecho, La historia me absolverá prefigura un futuro para la Revolución que comienza, y lo resume en el título con que alcanzó difusión el texto, extraído de su enunciado final: "Condenadme, no importa. La historia me absolverá" (Castro, La historia me absolverá, 129). Con gesto inaugural, Castro formula un porvenir político inequívoco - visible aun desde su presente - y propio del enunciador en tanto voz de toda una nación, pues señala al tiempo utópico de "Cuando Cuba sea libre" (95). Allí, una "verdadera justicia" (100) desbaratará las "meras apariencias" (18) del régimen jurídico vigente y, junto a ellas, acabarán disueltos los papeles de acusadores e imputados, que la dictadura de Batista impone para el juicio: "ahora estáis juzgando a un acusado, pero vosotros, a su vez, seréis juzgados no una vez, sino muchas, cuantas veces el presente sea sometido a la crítica demoledora del futuro" (101), prevé en ese sentido el líder.

El alegato pone en cuestión papeles históricos, y no sólo jurídicos (Giraudo, Revolución..., 54): es la Revolución entendida como justicia histórica que, según prescribe Castro, debe sobreponerse al engaño de la justicia imperante. En su argumento, la acción revolucionaria aparece como posición válida frente al autoritarismo que representa Batista, legítima no sólo de acuerdo a una convicción política específica, sino por humana y universalmente verdadera: "El derecho de rebelión contra el despotismo [...] ha sido reconocido, desde la más lejana antigüedad hasta el presente, por hombres de todas las doctrinas, de todas las ideas y todas las creencias" (122). La Revolución realiza, así, una verdad universal, fuerza histórica irreductible, por sí misma garante del orden de

${ }^{11}$ En la década de 1960, el texto se editó en Lima (Futuro, 1961), Santiago de Chile (1964), Buenos Aires (Hemisferio, 1965, Quetzal, 1973), además de contar con múltiples reediciones en Cuba. Acerca del proceso editorial del alegato, véase Giraudo (Revolución..., 23, 24) y Rojas (El juicio del Moncada). 
justicia y verdad cuya voluntad de construcción encarna Castro: “Admito y creo que la revolución sea fuente de derecho" (110), señala, y otorga a la Revolución, así, un estatuto de verdad a priori que habilitaría el paso, en el futuro proyectado para Cuba, a un sentido diverso, radicalmente otro, de lo que habrá de concebirse como ley.

Dicho de otra manera, la defensa no es sólo la de un acusado que busca mostrarse inocente, sino de toda una legalidad revolucionaria, de la cual Fidel y los asaltantes al Moncada que él representa constituyen realizaciones humanas, y en cuyos parámetros el juicio celebrado carece de cualquier legitimidad. La autodefensa de Castro, así, desplaza la quaestio judicial hacia el terreno político, ya que sólo en su campo, donde se ha decidido la sublevación contra Batista, el conflicto cobra sentido: "se está debatiendo algo más que la simple libertad de un individuo", afirma así Castro, "se juzga sobre el derecho de los hombres a ser libres, se debate sobre las bases mismas de nuestra existencia como nación civilizada y democrática" (22).

Es, pues, la ilegitimidad del juicio lo que invalida las posiciones enunciativas dispuestas para su celebración. Así, el doble lugar de abogado defensor y acusado que ocupa Castro aparece como una imposición del régimen de Batista, rechazada, sin embargo, en el espacio de sentidos de que el enunciador se apropia al comienzo del alegato:

Nunca un abogado ha tenido que ejercer su oficio en tan difíciles condiciones: nunca contra un acusado se había cometido tal cúmulo de abrumadoras irregularidades. Uno y otro son, en este caso, la misma persona. Como abogado, no ha podido ni tan siquiera ver el sumario y, como acusado, hace hoy setenta y seis días que está encerrado en una celda solitaria, total y absolutamente incomunicado, por encima de todas las prescripciones humanas y legales (9).

Resulta notable la distancia que en este fragmento Castro adopta respecto de los papeles que le adjudica el juicio, situados en el ámbito del tercero discursivo. El discurso denuncia así, en términos políticos, lo irregular e "insólito" (15) del caso, como impugnación inaugural bajo cuyo lema el discurso asumirá, en lo sucesivo, la primera persona. Entonces, dos construcciones enunciativas básicas regirán la alocución: por un lado, la narración testimonial de los hechos que protagoniza el 
imputado; por otro, la argumentación jurídica que corresponde a Fidel como defensa, en su rango de abogado.

El testimoniante que, por una parte, Castro encarna en La historia me absolverá, describe una figura de enunciador que cobrará especial legitimidad en el proceso revolucionario cubano - tal que, al finalizar la década de 1960, los escritores y críticos le proveerán el estatuto de un nuevo género literario -.${ }^{12} \mathrm{Al}$ dar testimonio de los hechos del Moncada, el líder habla desde la validez que provee una experiencia pasada, el haber sido testigo visual de la violencia del régimen dictatorial de Batista, pero también una de sus víctimas: "sólo quien haya sido herido tan hondo, y haya visto tan desamparada la patria y envilecida la justicia, puede hablar en una ocasión como ésta con palabras que sean sangre del corazón y entrañas de la verdad" (9). ${ }^{13}$

Así, la configuración de Fidel como testimoniante pone en palabras un desplazamiento subjetivo por el cual él, cuerpo leso de la víctima que ha sobrevivido, toma distancia de sí y de los otros - también víctimas: sus compatriotas - para ver el crimen desde fuera, como testigo, y proceder a juzgarlo. Es desde una distancia tal que se instala la situación política del enunciador, como rumbo que extrae al damnificado de su posición sufriente y pasiva, y lo redefine como hombre de acción. De ahí que los que restan vivos de "los crímenes horribles" (16) perpetrados en la represión del Moncada, y sobre todo Castro, constituyan la voz notable de un sujeto político que construye la autodefensa de Fidel: el pueblo cubano, todo él violentado por el régimen de Batista, víctima de "la opresión más cruel e inhumana de toda su historia" (13).

Fidel representa, pues, a un testimoniante superstes, resto vivo de la muerte generalizada que prefigura el estado dictatorial de Batista - "De tanta miseria sólo es posible liberarse con la muerte; y a eso sí los ayuda el Estado: a morir" $(62)^{14}$ - y que habrá de combatirse, acaso paradóji-

${ }^{12}$ Quintero Herencia observa un "afán testimonial que pareció redefinir las funciones de los géneros discursivos en la Isla" (Fulguración..., 350), vinculado a la puesta en sentido de la experiencia revolucionaria en el período comprendido entre 1960 y 1971. En la misma línea, Morejón Arnaiz señala la importancia del testimonio en los discursos públicos del campo cultural latinoamericano de los años sesenta ("Testimonio...", 93).

${ }^{13}$ Las cursivas son mías.

${ }^{14}$ El testimoniante sobreviviente, que reenvía a su origen etimológico en el término superstes, ha sido descrito por Agamben en su significación política contemporánea. 
camente, hasta la misma muerte, como se verá en el Diario del Che en Bolivia.

Ahora bien, en lo que hace a La historia me absolverá, el enfrentamiento a la dictadura, que resitúa el testimonio de una opresión en la práctica política que permitirá superarla, va asociado, por los lugares enunciativos que el contexto judicial impone, a una segunda faceta de su enunciador líder: la del letrado, en la inscripción jurídica y literaria a la que doblemente reenvía el término. Así, Castro se muestra en el alegato como quien habla porque ha leído, hombre ligado a la cultura escrita que circula en los libros, y que el texto despliega de manera retórica, no sólo en numerosas citas de filosofía política y del derecho que justifican la rebelión contra la tiranía de Batista, sino también en diversas evocaciones de piezas literarias. Se integran a la argumentación, en efecto, alusiones a Balzac, Dante y, profusamente, a José Martí, personificación ejemplar, en la historia de Cuba y Latinoamérica, de una vida y obra en que resultan inseparables la tarea literaria y la acción política.

Sería célebre la caracterización del Apóstol Martí como "autor intelectual del 26 de julio", formulada en La historia me absolverá (18). Allí, Castro se presenta como heredero del legado revolucionario martiano y, en ese acto, funda una noción singular de "obra", no ya individual, como en la tradición del autor literario, sino colectivamente fundada: acción política cuya necesidad histórica sostienen tanto los revolucionarios ya muertos, como el conjunto de rebeldes que intervinieron en el asalto al Moncada. ${ }^{15}$

Se ve, pues, cómo, interpretada en el terreno político donde se desarrolla la autodefensa de Fidel, la literatura participa de la legitimación de su práctica revolucionaria, así como de su posición líder en el proceso en cuestión, a saber:

Para el autor, la figura alude a quien ha vivido una cierta realidad hasta el final y puede dar testimonio de ella (Lo que queda de Auschwitz..., 15), pero fundamentalmente a un rasgo propio del siglo $\mathrm{xx}$, cuya característica violencia totalitaria define como supervivencia la vida de los sujetos (152).

${ }^{15}$ En esta línea, Quintero Herencia ha visto en las "Palabras a los intelectuales" de Castro una prescripción del "obrar" bajo el significado de "situarse en un mapa moral" (Fulguración..., 353, las cursivas son mías). Sobre Fidel Castro como legatario de la revolución martiana, en perspectiva discursiva, puede verse el análisis de Giraudo (Revolución..., 115). 
Os voy a referir una historia. Había una vez una república. Tenía su Constitución, sus leyes, sus libertades, Presidente, Congreso, tribunales; todo el mundo podría reunirse, asociarse, hablar y escribir con entera libertad. El gobierno no satisfacía al pueblo, pero el pueblo podía cambiarlo y ya sólo faltaban unos días para hacerlo. [...] Este pueblo había sufrido mucho y si no era feliz, deseaba serlo y tenía derecho a ello [...] Toda su esperanza estaba en el futuro. Ocurrió entonces que un humilde ciudadano de aquel pueblo [...] buscó un Código de Defensa Social para ver qué castigos prescribía la sociedad para el autor de semejante hecho (Castro, La historia me absolverá, 103-104);

y, más adelante,

Señores magistrados: yo soy aquel ciudadano humilde que un día se presentó inútilmente ante los tribunales para pedirles que castigaran a los ambiciosos que violaron las leyes e hicieron trizas nuestras instituciones, y ahora, cuando es a mí a quien se acusa de querer derrocar este régimen ilegal [...], se me traslada a este hospital para juzgarme secretamente con toda severidad y un fiscal con el Código en la mano, muy solemnemente, pide para mí veintiséis años de cárcel (109).

El alegato refuerza aquí la invalidez de la acusación por la que tiene lugar, así como la futilidad de impugnar el régimen político que origina el juicio por la vía ciudadana, adaptada a los parámetros de la ley vigente, que ha representado el abogado Castro. El juicio del Moncada podrá considerarse fundacional porque es allí que Fidel "inventa" la Revolución: una nueva ley histórica, que lo tiene como líder e impulsor, y ubica al pueblo como fundamento de su legitimidad política. El inicio literario del "Había una vez", enraizado en la tradición popular, se reformula para dar comienzo a un relato político, donde lo que existía antes se opone a lo que la palabra misma define como un quiebre: aquello que advendrá, cuando se parta del ahora.

De hecho, consideradas en su conjunto, la revolución cubana y su expansión continental muestran la voluntad de quienes las impulsaron de volver realidad política latinoamericana un gran relato revolucionario cuya fundación se ubicaba en el Moncada. Ahora bien, una causa tal - menos jurídica que política - desafiaba no sólo la capacidad de los movimientos de izquierda regionales de resultar absueltos en los 
procesos dominantes que los imputaban - como en el rumbo señalado en "la historia me absolverá" - sino, más radicalmente, su potencial para definir con parámetros propios las condiciones del juicio histórico en marcha. Los momentos triunfales del proceso hablan de dicho potencial, y es a su escena primera, narrada en el testimonio de Ernesto Guevara, al que nos abocamos en el siguiente apartado.

\section{Dilemas de la vida revolucionaria en los 'Pasajes' de Ernesto Guevara}

$\mathrm{Si}$, en sentido antropológico, los "pasajes" describen un tránsito (entre edades, situaciones o etapas) como manera de ser de la vida del hombre, la acepción del término como género de textos evoca, asimismo, un transcurrir: desplazamiento de la escritura en el tiempo y el espacio que pasan, o en la serie fragmentaria de experiencias que definen, en su pluralidad aun irreductible, un solo momento, pasible de ser reunido en lo unívoco de un objeto libro. ${ }^{16}$

Con ese nombre designados, los Pasajes de la guerra revolucionaria de Ernesto Guevara relatan la revolución cubana como proceso incompleto, sucesión acotada de episodios inscritos en un trayecto histórico que - cuando el libro se publica por primera vez, en 1963 - todavía no ha concluido, y tampoco define tajantemente un inicio, pues, según señala el autor: "Sus antecedentes habría que buscarlos muy atrás en la historia de Cuba" (Guevara, Obra..., 259). En efecto, el libro de Guevara despliega otra dificultad que recorre la militancia revolucionaria de los sesenta y setenta latinoamericanos, tejida entre los requerimientos de un presente al que apremia la tarea política, y la necesidad de "detener el tiempo" y reflexionar sobre el pasado, ya que es en su intento de estabilización que el presente puede cobrar sentido:

Desde hace tiempo, estábamos pensando en cómo hacer una historia de nuestra Revolución que englobara todos sus múltiples aspectos y

${ }^{16}$ Se encuentra en Les rites de passage de Van Gennep la noción antropológica del pasaje. Para el autor, la vida de los hombres consiste en pasos sucesivos de una situación a otra, pasos que son regulados socialmente en prácticas ritualizadas de su elaboración simbólica (Ritos de paso, 15). 
facetas; muchas veces los jefes de la misma manifestaron — privada o públicamente - sus deseos de hacer esta historia, pero los trabajos son múltiples, van pasando los años y el recuerdo de la lucha insurreccional se va disolviendo en el pasado sin que se fijen claramente los hechos que ya pertenecen, incluso, a la historia de América. Por ello, iniciamos una serie de recuerdos personales de los ataques, combates, escaramuzas y batallas en que intervinimos. No es nuestro propósito hacer solamente esta historia fragmentaria a través de remembranzas y algunas anotaciones; todo lo contrario, aspiramos a que se desarrolle el tema por cada uno de los que lo han vivido. Nuestra limitación personal, al luchar en algún punto exacto y delimitado del mapa de Cuba durante toda la contienda, nos impidió participar en combates y acontecimientos de otros lugares $[\ldots](114) .{ }^{17}$

Como la forma pasaje, el recuerdo es fragmentario, y, consiguientemente frágil, aun cuando la escritura de la Revolución pretenda "englobarlo" todo, restituyendo su totalidad inasequible. El texto se retrotrae a la lejanía de un tiempo ya algo difuso, uno que, con el correr de los años, se ha ido "disolviendo" en la memoria del escritor, y de allí la incompletud del relato, su rango confeso de mera "anotación". Así, incapaz de restituir in toto lo vivido, la operación de memoria define para los Pasajes de la guerra revolucionaria una fragmentariedad que va ligada, además, al carácter mismo de la vivencia rememorada, pues ella representa sólo una experiencia parcial, recortada en el "punto exacto y delimitado del mapa" que ocupó el narrador. Las lagunas de la memorización propia procurarán saldarse, eventualmente, en los testimonios de otros, como si allí, en el ensamblado de múltiples sesgados relatos, terminara por surgir la verdadera Historia.

El libro del Che pone de relieve, en efecto, las dificultades propias del testimonio como intento de reconstrucción del pasado, donde entran en cuestión tanto la fiabilidad del recuerdo - más amenazada al ser extensa la distancia respecto del pasado que se recupera - como la posibilidad misma de que el discurso dé cuenta cabal y completa de la experiencia que constituye su objeto. ${ }^{18}$ Ahora bien, más todavía, la narración

${ }^{17}$ Las cursivas son mías.

18 “Hasta qué punto es fiable el testimonio?”, se pregunta Ricoeur en esta línea ( $\mathrm{La}$ memoria..., 209), pues, como aserción de una realidad pasada, el testimonio se sitúa entre 
de Guevara enfrenta los problemas que atraviesan la construcción de la memoria cuando se trata particularmente de la práctica revolucionaria. En este caso, la puesta en relato de la experiencia se ve limitada por las condiciones de realización del proceso de lucha, proceso en que - contra el irreductible acto de lenguaje que implica dar testimonio, y según la frecuencia en que se remarcaría en la obra del Che escritor - debe imperar un silencio riguroso. La escena del entierro de Eutimio Guerra, incluida en el episodio "Fin de un traidor", resulta significativa en este sentido:

Al día siguiente, lo enterramos allá mismo y hubo un pequeño incidente que recuerdo. Manuel Fajardo quiso ponerle una cruz y yo me negué porque era muy peligroso para los dueños de la hacienda que quedara ese testimonio del ajusticiamiento. Entonces grabé sobre uno de los árboles cercanos una pequeña cruz. Y esa es la señal que indica dónde están enterrados los restos del traidor (141).

Son suficientemente conocidas las elaboraciones teóricas de Guevara, sobre todo conceptualizadas en La guerra de guerrillas, acerca del mutismo y la clandestinidad que requiere la actividad guerrillera en su fase defensiva. ${ }^{19}$ En tales circunstancias, el guerrillero debe evitar ser visto y oído por los enemigos efectivos y potenciales; de allí que, en la escena citada, sea necesario volver menos perceptible la huella fatal de la acción revolucionaria que podría representar la cruz. El mismo problema aqueja a la escritura del proceso revolucionario durante su consecución; por eso los Pasajes de la guerra revolucionaria son la reescritura de un diario de secreto del combatiente que sólo se publicaría décadas más tarde, mucho después de acaecida la muerte a cuyo peligro lo exponía la lucha guerrillera. ${ }^{20}$

Así, la acción revolucionaria en la guerrilla se sobrepone a la escritura y a la ayuda-memoria que esta podría representar. La lucha gue-

la confianza pedida a un otro que ha de creer, y la sospecha que acecha siempre al recuerdo, desacreditándolo como posible ficción, alucinación o mentira.

${ }^{19}$ Sostenía Guevara que "La primera base sobre la que debe establecerse el movimiento, es sobre un secreto absoluto, sobre la total ausencia de informaciones para el enemigo" (Obra ..., 94).

${ }^{20}$ Nos referimos al Diario de un combatiente, editado en 2011, que contiene anotaciones de Guevara realizadas desde diciembre de 1956 hasta enero de 1959. 
rrillera ofrece más condiciones para su experiencia que para su relato; define, planteado de otro modo, una vida que obtiene su intensidad del hecho de que se aboca, primero, a defenderse como tal de la muerte. Las necesidades de la escritura, incluida la simpleza aparente del papel que la hace materialmente posible, aparecen fútiles frente al riesgo que corre la vida, como ocurre al protagonista en su intervención como médico de la guerrilla, durante el combate del cuartel del Uvero: "Leal estaba desmayándose, mientras empezaba la parálisis de los miembros de un costado del cuerpo [...]. El único vendaje que tenía a mano era un pedazo de papel que coloqué sobre las heridas" (167), cuenta, en ese episodio, el narrador Guevara. ${ }^{21}$

Así, los Pasajes de la guerra revolucionaria constituyen una reconstrucción ulterior del pasado revolucionario, que intenta sortear las dificultades de la escritura en la Revolución. Pero, además, reafirman la proyección a futuro que había inaugurado La historia me absolverá, pues las perspectivas del proceso en curso no surgen sino de un balance de lo visto y vivido. En un contexto tal, la designación del libro bajo la noción del "pasaje" posee otras connotaciones. En particular, alude - más cerca de la acepción antropológica que mencionábamos al comienzo - al traspaso de un modo de ser del hombre a otro; un cierto aprendizaje que para el narrador, el Che, implicó la lucha guerrillera, y que el texto busca enseñar al lector:

[...] en ese momento un compañero dejó una caja de balas casi a mis pies, se lo indiqué y el hombre me contestó con cara que recuerdo perfectamente, por la angustia que reflejaba, algo así como "no es hora para cajas de balas", e inmediatamente siguió el camino del cañaveral [...]. Quizá esa fue la primera vez que tuve planteado prácticamente ante mí el dilema de mi dedicación a la medicina o a mi deber de soldado revolucionario.

Tenía delante una mochila de medicamentos y una caja de balas, las dos eran mucho peso para transportarlas juntas; tomé la caja de balas, dejando la mochila para cruzar el claro que me separaba de las cañas $[\ldots]$.

Cerca de mí un compañero llamado Arbentosa, caminaba hacia el cañaveral. Una ráfaga que no se distinguió de las demás, nos alcanzó a los

${ }^{21}$ Otro segmento la narración agrega que "había muy poco papel en la Sierra" (163). 
dos. Sentí un fuerte golpe en el pecho y una herida en el cuello; me di a mí mismo por muerto (115).22

El fragmento, muy conocido, corresponde a "Alegría de Pío", el primero de los episodios de combate del libro, que condensan el sentido épico de la lucha revolucionaria. ${ }^{23}$ Ahora bien, la importancia de este segmento narrativo inaugural reside en el aspecto dilemático que concede a la figura del hombre de la Revolución, encarnado ejemplarmente por el Che. En efecto, el momento dramático del combate hace patente una escisión interna del revolucionario, en la imagen paradójica -e imposible - del salir de sí y "darse por muerto". Guevara se halla en esta escena frente a la dificultad de una opción: ser médico y vivir como aquel que salva vidas, o ser revolucionario y, armas mediante, vivir predispuesto a la propia muerte, y a quitar la vida ajena. En ambos casos, se trata de compadecerse de otros, pero cuando el narrador toma las balas y no los medicamentos, decide el pasaje entre lo que percibe como dos espacios simbólicos opuestos, que lo configuran como sujeto y se definen en oposición recíproca: de ese modo, al éxito profesional individual que habilitaba su rol de médico vendría a sobreponerse en fin el triunfo político colectivo que implica conseguir la Revolución. Ricardo Piglia ha observado cómo el par dicotómico literatura/política interviene crucialmente en el rito de pasaje (El último lector, 126), según muestra más adelante el relato de "Alegría de Pío":

Quedé tendido, disparé un tiro hacia el monte siguiendo el mismo oscuro impulso del herido. Inmediatamente, me puse a pensar en la mejor manera de morir en ese minuto en que parecía todo perdido. Recordé un viejo cuento de Jack London, donde el protagonista, apoyado en un tronco de árbol, se dispone a acabar con dignidad su vida, al saberse condenado a muerte por congelación, en las zonas heladas de Alaska. Es la única imagen que recuerdo. (Guevara, Obra..., 115)

Interpretada por Piglia, la escena instala la imagen de Guevara como un último lector, pues, en lo que siga al encuentro con su propia muerte,

${ }^{22}$ Las cursivas son mías.

${ }^{23}$ Duchesne ha señalado la importancia de los combates en los relatos de Guevara, como momentos estelares del proceso revolucionario, nodales en la construcción de la trama narrativa (Narraciones..., 87). 
sólo quedará de él un "hombre práctico en estado puro", que ha abandonado la literatura y la profesión médica al decidir su máxima condición de hombre político, guerrillero (El último lector, 106). Importa reparar, sin embargo, en un desfase del Che lector que revela la narración al reescribir el cuento de Jack London, "To build a fire", pues el personaje de London no muere apoyado en un tronco de árbol, sino tirado en el hielo. Junto a un árbol, en cambio, se encuentran Guevara y su compañero Montané conversando antes del inicio del tiroteo, según cuentan los Pasajes de la guerra revolucionaria. La inminencia de la muerte hace surgir en quien escribe el anhelo de una "mejor manera" de sí mismo, o la realización completa de su potencial humano, pero, justamente allí, en el anhelo de un ser completo, ocurre la falla en la lectura: de acuerdo a la nueva versión del escritor estadounidense, la manera mejor de sí sería, para el Che que escribe, el guerrillero en combate que él ya es allí, recostado contra el árbol, y no tanto el hombre de libros que frecuentaba a London.

El desfase surge entre lo que se dice y la experiencia que intenta decirse. En efecto, la "mejor manera de morir" de la que habla Guevara no existe, simplemente porque, en la muerte, nada se vive, nada es mejor ni peor; y tampoco existe una mejor manera de vivir, porque la totalidad de sí a la que aspira una existencia sólo es posible al intentar dar sentido, en vida, a la experiencia imposible que constituye la muerte. Precisamente, la escena narra una vida como dilema: problema que carece de solución y que, por lo tanto, aparecerá representado no sólo en esa "primera vez" del combate del Che, ni en el conjunto de su vida y obra - incluido, como veremos, el Diario de Bolivia - sino, más generalmente, en el recorrido complejo del vínculo entre literatura y política en los sesenta y setenta latinoamericanos.

Es que el revolucionario describe una relación social: la individuación de una condición histórica que lo toca como a un "uno entre otros", y que adquiere parte de su carácter en el hecho, políticamente necesario, de constituir la pieza singular de un todos. De ahí el nosotros que domina la narración de los Pasajes de la guerra revolucionaria, y de ahí también la importancia de la figura de Fidel Castro en el devenir guerrillero que sus episodios relatan. Es célebre, en ese sentido, la escena en que el líder cubano lo nombra comandante y le entrega la estrella de cinco 
puntas que el Che usaría en su boina, pues, con ese acto de renombre, y en papel de iniciador, Fidel fija para Guevara un rango de revolucionario en cuya instancia final, la experiencia armada boliviana, también él tomará la palabra. A esa nueva escenificación testimonial de los dilemas de latinoamericanos de los años sesenta y setenta, nos dedicamos en el próximo apartado.

\section{Del testimonio al testamento: el 'Diario del Che en Bolivia'}

El Diario del Che en Bolivia apareció por primera vez en 1968, con múltiples ediciones en Cuba y otros países de América y Europa.$^{24} \mathrm{La}$ publicación del libro participa de una construcción póstuma de la figura heroica del Che, en que su definición como encarnación mayor de la lucha revolucionaria se aunaba a la canonización de su obra de escritor. La operación había sido sugerida en los círculos literarios cubanos ya en la primera mitad de los años sesenta, con la publicación de Pasajes de la guerra revolucionaria, ${ }^{25}$ pero sería después de la muerte de Guevara que su fama de escritor surgiría con más fuerza, e incluso convalidada dentro del campo político. Así, en el discurso que en octubre de 1967 pronunció en memoria del guerrillero, Fidel Castro atribuyó a su escritura "la virtuosidad de un clásico de la lengua", ligando a su papel de narrador la superioridad irrepetible de su figura revolucionaria: "Sus narraciones de la guerra son insuperables", decía allí Fidel, en una consideración que, eventualmente, haría suya un sector de escritores y críticos del campo latinoamericano. ${ }^{26}$

Desde un punto de vista histórico, y frente al texto anterior de Guevara, el Diario representa tanto avances como obstáculos de la práctica

${ }^{24}$ Además de editarse en La Habana, por el Instituto Cubano del Libro, en 1968 el libro se publicó en México, Lima, Bogotá, Madrid, París, Nueva York y Londres.

${ }^{25}$ Según Fernández Retamar, ya en 1962 Nicolás Guillén propuso a Guevara incorporarse a la Unión de Escritores y Artistas de Cuba, pero aquél lo rechazó porque "no se consideraba escritor" ("Prólogo", 11).

${ }^{26}$ José Portuondo cita este pasaje en sus "Notas preliminares sobre el Che escritor". Asimismo, Haydée Santamaría reconoce el editorial al número 46 de Casa de las Américas la canonización por Fidel Castro de la figura del Che: "este gran pueblo no sabía qué grados te pondría Fidel. Te los puso: artista" (3, las cursivas son mías). 
revolucionaria que ambos testimonian, y que, iniciada en Cuba, pretendía ahora afirmarse en su expansión continental. En ese contexto, si los Pasajes habían constituido una escritura ulterior de una revolución triunfante, la publicación del diario de combate del Che, trunco el día anterior a su muerte, provee la pauta de un proceso político con limitaciones, en cuya puesta en relato la retrospección reflexiva no aparece como del todo posible. De allí el acercamiento al puro presente que intenta, en su práctica cotidiana, la forma del diario, y de allí también que Fidel Castro ocupe en la "introducción necesaria" al libro el lugar de un autor que ya no está, como si en su liderazgo se reasegurase la continuidad de la historia que comenzó más de una década atrás. La suplencia ejercida por el líder se valida en tanto, según él estipula, la Revolución supera lo contingente de la muerte individual por la necesidad -o el estatuto de ley - que otorga a la historia colectiva: "Che contemplaba su muerte como algo natural y probable en el proceso y su eventualidad no impediría la marcha inevitable de la Revolución en América Latina" (XIII), reafirmaba así, en la instancia cúlmine del rol de iniciador que ocupaba en los Pasajes, el prologuista póstumo, Fidel.

En efecto, las figuras de Castro y Guevara plantean, de modo más patente al intervenir la muerte, el estatuto complejo de la individualidad en un proceso político que impone su realización colectiva. La contingencia eventual de cada revolucionario muerto puede terminar objetando, si se reitera en el tiempo y/o el espacio, al multiplicarse las derrotas, el carácter necesario - dado a priori- de una historia que requiere de hombres vivos para su efectiva consecución. Fidel alude al Che, entonces, como un revolucionario más, aun muerto, para promover la réplica "entre los pueblos explotados en este continente" (XIII) de una acción política que continúa y que, sin embargo, ha dependido crucialmente de la unicidad irreductible de sus líderes y sus héroes, como lo deja ver el acto mismo de la publicación del Diario, bajo la tutela de Castro en la introducción.

Es que, más que cualquier otro texto de Guevara, el Diario de Bolivia coloca a la muerte en el primer plano del relato, y manifiesta, en ese sentido, un aspecto testamentario que atraviesa la práctica testimonial, como dispositivo enunciativo básico para la puesta en sentido de la experiencia de la Revolución en los años sesenta latinoamericanos. Así, 
jurídicamente codificado como el testimonio, el testamento da fe de una última voluntad del sujeto que cuenta como tal al acaecer la muerte, y que dispone para una posteridad, quienes después quedan vivos, un conjunto de sus bienes: aquellos que, asimismo, sobrevivirán a quien atesta. En el caso de la vida revolucionaria, el problema es la potencia con que en su discurrir intenso y riesgoso se inscribe la muerte; de allí que, potencialmente, cualquier voluntad revolucionaria, más aún cuando se deja escrita, pueda resultar una última voluntad.

De esa forma ocurre con la obra del Che. Luego de su muerte, su obra será interpretada, en parte, como el legado póstumo de una práctica revolucionaria que, con la falta de su persona, debe aún sobrevivir. En la Obra revolucionaria compilada por Fernández Retamar, citada más arriba, es el célebre ensayo El socialismo y el hombre en Cuba, de 1965, que para el crítico llegó a "adquirir cierto carácter testamentario" (21). Pero, entre todos los textos de Guevara, será especialmente el "Mensaje a los pueblos" aparecido en la revista Tricontinental en abril de 1967, cuando aquel ya se encontraba en Bolivia, que se interpretará como el testamento político del guerrillero. El mensaje constituía, de hecho, la advocación a una revolución mundial necesaria, junto a la instanciación pública de una eventual bienvenida a la muerte que su intento de realización, meses más tarde, efectivamente implicaría para Guevara. ${ }^{27}$

La muerte, así, exhibe en la experiencia guerrillera la cotidianeidad expresada por la forma del diario, como si cada anotación nueva registrase los azares de un día sobrevivido más. Del mismo modo que sucedía en los Pasajes, el instante de la muerte inminente invita a un (re)encuentro con lo literario, y es en las notas de un "Día negro" que el Che, en homenaje a un compañero muerto, evoca "Un canto para Bolívar" de Pablo Neruda: "de su muerte oscura sólo cabe decir, para un hipotético futuro que pudiera cristalizar: 'Tu cadáver pequeño de capitán valiente ha extendido en lo inmenso su metálica forma"” (Guevara, Diario, 166). Corporizada en el cadáver del patriota latinoamericano, la muerte oscurece la inmensidad de un futuro que, entonces, aparece

${ }^{27}$ Luego de la muerte del Che, José Portuondo ("Notas preliminares...", 33) definía el mensaje de la Tricontinental como su testamento político. Mucho más tarde, así también lo han caracterizado Lowy (El pensamiento del Che, 95) y Kohan, quien lo señala como la elaboración política más madura de Guevara (Ernesto Che Guevara..., 54). 
como "hipotético" para quien seguirá viviendo, arriesgando su propia vida en la realización valiente de la obra revolucionaria en marcha. En un momento tal, sólo la literatura, y ya no la narración, como sucedía en los Pasajes, sino la poesía, pretende reparar aquello inenarrable siempre inscrito en la experiencia de la muerte.

Es posible observar cierto desplazamiento entre los Pasajes y el Diario, entre la short story de London y el canto poético de Neruda que ambos definen como "canon" del revolucionario que escribe. Las figuras de Neruda y Bolívar resumen una opción política, latinoamericanista y revolucionaria, en la Latinoamérica de la década 1960. Pero, además, su evocación define una particular relación del guerrillero con lo literario, donde cobra relevancia la matriz oral del discurso y, con ella, su posible memorización, que, más que la forma del cuento, surgen en el poema, sobre todo tratándose de uno de tono épico como el de Neruda. ${ }^{28}$

Así, lejos ya de los libros de aventuras, pervive en la memoria del guerrillero un eco épico de lo literario, cuya modernidad, junto a la del proceso revolucionario que aquel representa, reafirmará, no obstante, la impresión póstuma del libro. En la misma línea puede interpretarse la caracterización de la Revolución como "leyenda", en la ambigüedad de la palabra que repetidamente emplea el Che. ${ }^{29} \mathrm{El}$ Diario cuenta, en efecto, una historia que, como en el sentido etimológicamente derivado del término, ha de ser leída, allí en el libro que quede después de la muerte de Guevara, y otra menos fija que la palabra impresa y cercana al rumor, que debe adquirir "dimensiones continentales" (265) para reafirmarse como relato, y afianzar la realidad política a la que pretende proveer forma.

${ }^{28}$ Taibo II comenta en su biografía de Guevara que éste conocía y recitaba poemas de Neruda de memoria (Ernesto Guevara..., 69). Más discutido es el hecho, difundido por el mismo autor, de que el Che llevaba entre sus pertenencias un cuaderno verde cuyas páginas conformaban una antología manuscrita de poemas de Nicolás Guillén, León Felipe, César Vallejo y Pablo Neruda (12). De hecho, el reciente estudio de Kohan sobre los manuscritos de Bolivia no documenta una antología de poesías, y el cuaderno de tapas verdes que analiza contiene notas de economía y filosofía política (En la selva, 19, 20).

29 "La leyenda de la guerrilla crece como espuma; ya somos los superhombres invencibles" (231); "La leyenda de las guerrillas adquiere dimensiones continentales" (265); "Estamos en un momento de baja de moral y de nuestra leyenda revolucionaria" (298). 
Lo literario, pues, participa de la puesta en sentido de la Revolución en la escritura guerrillera del Che, por proveer un cariz estético a la experiencia que representa:

Debray [...], parece, habló más de lo necesario aunque no podemos saber qué implicaciones tiene esto [...]. Se rumora también que el Loro fue asesinado. Me atribuyeron ser el inspirador del plan de insurrección en las minas, coordinado con el de Nancahuazu. La cosa se pone linda; dentro de algún tiempo dejaré de ser "Fernando Sacamuelas" (230). ${ }^{30}$

La escena reitera el pasaje del médico que cura al revolucionario en combate que describía el libro anterior de Guevara, ya que una vez más la tarea guerrillera requerirá que "Fernando Sacamuelas" - como lo llaman los campesinos bolivianos, pacientes de sus extracciones dentales - vuelva a ocupar el lugar del Che. Ahora bien, en el curso político iniciado en el Moncada, que proveyó al narrador de su renombre internacional de revolucionario, el dilema inscrito en sus pasajes adopta, como respuesta aún momentánea y provisoria, la proyección de un matiz estético sobre la experiencia política, que disolvería la distancia entre sus espacios simbólicos: al señalar que "La cosa se pone linda", el Che afirma que, en la cotidianeidad de la guerrilla, un máximo potencial estético se revela junto a su mayor carácter político, cifrado en el episodio épico e inminente del combate.

Es que el combate, de hecho, pondrá en acto el antagonismo rector de lo político, enfrentando al guerrillero con lo real e intolerable de la muerte, ${ }^{31}$ y de allí que sea en su momento que surja la significación estética de la vivencia revolucionaria. La salida estética se reitera en la finalización del diario: "Se cumplieron los 11 meses de nuestra inauguración guerrillera sin complicaciones, bucólicamente" (345), ${ }^{32}$ señala Guevara, a modo de balance, en las anotaciones del 7 de octubre, en lo

${ }^{30}$ Las cursivas son mías.

${ }^{31} \mathrm{El}$ antagonismo, concepto que recoge la dimensión constitutivamente conflictiva de lo político, define la distinción nosotros-ellos como condición de formación del sujeto político (Mouffe, En torno a lo político, 23). Sobre la relación entre el antagonismo y la muerte, en cuanto núcleo real-traumático de la constitución del sujeto, reenviamos a Žižek (El sublime objeto..., 176 y ss.).

${ }^{32}$ Las cursivas son mías. 
que resultaría el último registro de la experiencia boliviana. A la luz de los sucesos siguientes, la docilidad de la situación diagnosticada por el Che puede aparecer como paradójica, e incluso como un error histórico, como si el sentido de belleza de la acción en la Revolución hubiese culminado opacando la racionalidad de su análisis político. No obstante, hasta su presente de enunciación, una caracterización tal - poéticade la práctica política, como si de su hacer emergiese un canto, acaso constituyó un modo de hacer vivible la experiencia revolucionaria. ${ }^{33}$

\section{Apuntes finales sobre testimonio literario y política en Latinoamérica}

Si el testimonio se ha estabilizado como género en el campo literario latinoamericano, ello se debe en parte a la relectura que durante la década de 1960 ciertos escritores y críticos efectuaron sobre el discurso revolucionario de la época, así como a condiciones que la misma producción del discurso revolucionario procuró, al poner en palabras, lazos diversos entre la práctica literaria y la acción política. La literariedad peculiar del testimonio, en efecto, intenta volver justeza estética lo que para la izquierda cultural de la etapa hacía la justicia política de América Latina, con Cuba como pionera y modelo. En esa línea, el género instituye en su valor literario la figura de quien escribe en tanto ha visto, sentido y actuado la realidad política latinoamericana, figura que, como vimos, Castro esgrimía en su defensa en el juicio del Moncada, y que se reformularía, incluso hasta después de la muerte, en los relatos guerrilleros del Che.

Un evento crucial en la fundación del testimonio, el certamen literario Casa de las Américas de 1970, convocaba a quien quisiese devenir escritor del género a "documentar un aspecto de la realidad latinoamericana o caribeña por una fuente directa", especificando que "Se entiende

${ }^{33}$ Melgar Bao ha estudiado la elaboración simbólica de la muerte en las guerrillas latinoamericanas, requerida por su cotidianeidad en la lucha. Tal elaboración va ligada, según el autor, a rituales de protección de la vida, de puesta en memoria de los compañeros caídos y de aprendizaje de modos de aniquilamiento de presuntos traidores y enemigos ("La memoria sumergida...", 49). 
por fuente directa el conocimiento de los hechos por su autor y su compilación de relatos o evidencia obtenidos de los individuos involucrados o de testigos calificados" (apud. Beverley, Testimonio, 103) ${ }^{34}$ Formulada en esos términos, la convocatoria planteaba una cuestión sobre el estatuto de la práctica literaria y su relación con la política, que interesa plantear aquí, pues recorre el género testimonial en su conjunto: ¿"conocimiento de los hechos por su autor" o "compilación de relatos o evidencia" ajenos? Dicho de otro modo, ¿sentir la realidad política latinoamericana en cuerpo propio, o hacerse oídos para un relato aún protagonizado por otros? La ambigüedad en la legitimidad genérica del testimonio escenificaba nuevamente un dilema, pues si en la última alternativa el escritor corría el riesgo de volverse demasiado tradicional, al regresar a su histórico escritorio luego de recolectar la vida de los actores políticos o el "pueblo"; el conocimiento propio de los hechos, en cambio, se arriesgaba a convertirse en tan revolucionario que borrase cualquier singularidad, e incluso existencia, de la práctica literaria. Había que estar allí - no sólo enfocar, sino sobre todo vivir una experiencia política sobre la cual, ejemplarmente, el discurso revolucionario cubano ya había legado su testimonio - pero tal voluntad de cuestionar los límites de lo literario culminaba, llevada hasta sus últimas consecuencias, en la disolución de sus mismos lugares de enunciación de los escritores y los críticos literarios que promovían la institucionalización del testimonio. ¿Bajo qué forma, pues, se haría posible la literatura en el mundo nuevo, si allí los escritores fueren no tales ya, sino revolucionarios?

\section{REFERENCIAS}

Agamben, Giorgio, Lo que queda de Auschwitz. El archivo y el testigo. Homo sacer III [1998], trad., Antonio Gimeno Cuspinea, Valencia, Pre-textos, 2000. Arendt, Hannah, Sobre la revolución [1965], trad. Pedro Bravo, Madrid, Alianza, 2008.

Aymerich, Carmen, La memoria en el espejo: aproximación a la escritura testimonial, Barcelona, Anthropos, 1998.

${ }^{34}$ La traducción es mía. 
BARNET, Miguel, "La novela testimonio: socio-literatura", Unión, núm. 4, 1969, 99-122.

Beverly, John, Testimonio: on the politics of truth, Minneapolis, University of Minnesota Press, 2004.

Castro, Fidel, La historia me absolverá [1953], La Habana, Ediciones Populares, 1961.

Collazos, Óscar, Cortázar, Julio y Vargas Llosa, Mario, Literatura en la revolución y revolución en la literatura. Polémica [1969], México, Siglo XXI, 1970.

Duchense Winter, Juan, Narraciones del testimonio en América Latina: cinco estudios, San Juan, Universidad de Puerto Rico, 1992.

Fernández Retamar, Roberto, Para una teoría de la literatura hispanoamericana [1984], Bogotá, Instituto Caro y Cuervo, 1995.

Fernández Retamar, Roberto, "Prólogo a esta edición”, en Guevara, Ernesto, Pasajes de la guerra revolucionaria, La Habana, Casa de las Américas, 1997, 7-23.

García, Victoria, "Testimonio literario latinoamericano. Una reconsideración histórica del género", Exlibris, núm.1, 2012,371-389.

Gilman, Claudia, Entre la pluma y el fusil. Debates y dilemas del escritor revolucionario en América Latina, Buenos Aires, Siglo XXI, 2003.

Giraudo, Silvia, Revolución es más que una palabra, Buenos Aires, Biblos, 2010.

Guevara, Ernesto. Diario del Che en Boliva. Noviembre 7, 1966 a octubre 7, 1967, Introducción de Fidel Castro, La Habana, Instituto Cubano del libro, 1968.

Guevara, Ernesto, Diario de un combatiente, Buenos Aires, Ocean Sur, 2011.

Guevara, Ernesto, Obra revolucionaria, México, Era, 1967.

Guevara, Gustavo, La revolución cubana, Madrid, Dastin, 2006.

KoHan, Néstor, Ernesto Che Guevara. El sujeto y el poder, Buenos Aires, Nuestra América, 2005.

Kohan, Néstor, En la selva, Santiago de Chile, Rodrigusta, 2011.

Lowy, Michael, El pensamiento del Che Guevara [1970], trad. Aurelio Garzón del Camino, México, Siglo XXI, 2004.

Melgar Bao, Ricardo, "La memoria sumergida. Martirologio y sacralización de la violencia en las guerrillas latinoamericanas", en Movimientos armados en México: siglo xx, vol. I, O. Solano, V. y M. E. García Ugarte (coords.), México, El Colegio de Michoacán, Centro de Investigaciones y Estudios Superiores en Antropología Social, 2006, 29-68.

Morejón Arnaiz, Idalia, "Testimonio de una casa", Encuentro, núm. 94, 2006, 93-104. 
Mouffe, Chantal, En torno a lo político [2005], trad. Soledad Laclau, Buenos Aires, Fondo de Cultura Económica, 2007.

Piglia, Ricardo, El último lector, Barcelona, Anagrama, 2005.

Portuondo, José, "Notas preliminares sobre el Che escritor", Unión, núm. 4, 1967, 29-34.

Quintero Herencia, Juan Carlos, Fulguración del espacio. Letras e imaginario institucional de la Revolución Cubana (1960-1971), Rosario, Beatriz Viterbo, 2002.

Rama, Ángel. "Conversación en torno al testimonio" [1969], Casa de las Américas, 200, 1995, 122-123.

Ricoevr, Paul, La memoria, la historia, el olvido [2000], trad. Agustín Neira, Buenos Aires, Fondo de Cultura Económica, 2004.

Rojas, Marta, El juicio del Moncada, Córdoba, Espartaco, 2006.

Santamaría, Haydée, "Hasta la victoria siempre, Che querido", Casa de las Américas, 46, 1968, 3.

SchAEFFER, Jean-Marie, ¿Qué es un género literario? [1989], trad. Juan Bravo Castillo y Nicolás Campos Plaza, Madrid, Akal, 2006.

SklodowsKa, Elzbieta, Testimonio hispanoamericano: historia, teoría, poética, New York, Peter Lang, 1992.

Taibo II, Paco Ignacio, Ernesto Guevara también conocido como el Che [2003], México, Planeta, 2005.

VAN GenneP, Arnold, Los ritos de paso [1969], trad. Juan Aranzadi, Madrid, Alianza, 2008.

ŽıžEK, Slavoj, El sublime objeto de la ideología [1989], trad. Isabel Vericat Núñez, Buenos Aires, Siglo XXI, 2003. 